\title{
Editorial
}

\section{El verdadero rol de abuelo o una nueva puerta hacia la esclavitud}

El creciente ascenso del número de personas ancianas ocupadas en tareas permanentes que, a todas luces, deberían corresponderles a sus hijos, es un tema recurrente en distintos foros, formales o claramente distendidos.

Los que, por nuestra condición de padres entrados en años, visitamos con bastante frecuencia parques y columpios que otros recorrieron hace dos décadas, contemplamos a diario a una amplísima lista de abuelos o abuelas ocupados con la custodia y el entretenimiento de sus nietos en estos espacios de expansión. Lo que a priori podría retratar una eficaz y terapéutica fórmula de enriquecimiento para unos y otros, tiene en muchos casos un trasfondo donde el bondadoso "sunamitismo" se acerca más a fórmulas modernas de esclavitud que utilizan los férreos lazos afectivos por cadenas.

No quiero aludir a otras situaciones que entiendo extraordinarias, a pesar de su alta frecuencia, en las que los abuelos actúan como padres por pérdida-temporal o no- de éstos, lo que supone un seguro reconocimiento de acogida voluntaria por parte de esos abuelos ante unos nietos desamparados. A pesar de las dificultades mayúsculas de esta situación, aplaudo un papel heroico en esas acogidas, que requerirían de mayor atención social.

En estas líneas no quiero referirme a esa cantidad incontable de abuelos que ven, a diario o cada poco tiempo, a sus nietos y los acompañan al parque o disfrutan de un tiempo de rica convivencia, sino de aquéllos que, entre las actividades diarias con sus nietos, encajan la de visitar con ellos el parque, recogerlos del colegio y darles la merienda, antes de llevarlos de nuevo a casa y firmar el certificado de entrega a sus padres naturales.

A todo ello se suma el cansancio añadido de empezar la jornada -día sí y día tambiénrecibiendo a los niños a horas tempranas, llevándolos de un sitio a otro o, lo más gravoso, tutelándolos a jornada completa en su propia casa o en la de sus hijos, con una elevada responsabilidad y una implicación directa en las tareas de alimentación, higiene, vestido, entretenimiento y educación de los niños. A menudo, esta devastadora programación se completa con la misión ("siempre voluntaria y con la sonrisa puesta", eso sí) de dar de comer y facilitar el descanso a los exhaustos padres de los niños cuando llegan del trabajo.

En muchos casos, veo cómo esta apretada agenda y las elevadas dosis de estrés que conlleva convive con una aceptación estoica (total, sólo ocupa todo el tiempo libre de sus ansiadas y merecidas jubilaciones) y, pocas veces, se da una denuncia explícita del abuso ("ya que son los de mi sangre"). Creo que se trata, simple y llanamente, de un nuevo fenómeno de sometimiento. 
114 A buen seguro alguien me acusará de exageración por mi presentación de este panorama. Si llegara a muchos de esos mayores, voluntarios extemporáneos de la atención de sus nietos, tal vez lo considerasen desvirtuado, dado que ese rol que implica vocación y atención intensiva en las tareas de cuidado tiene un principio y un fin. Quizá si fuese una tribuna abierta, estas palabras no llegarían a aquéllos a quienes he querido dibujar, porque ni siquiera tendrían tiempo para leer esta columna.

A los profesionales gerontológicos, seguros lectores de estas líneas, quiero darles una llamada de atención. Mañana pueden tener frente a ustedes a un paciente mayor con manifestaciones clínicas, psíquicas, anímicas, etc., de profundo calado, relacionadas directamente con este nuevo síndrome y que será necesario tener en cuenta. Difícilmente ayudarán sus denuncias en el diagnóstico.

En cualquier caso, ojalá que este editorial recoja hoy una imagen irreal, distorsionada, infrecuente $y$, por ello, mal seleccionada por parte de este observador de parques y jardines.

J. Javier Soldevilla Agreda Director de Gerokomos

\section{A ti, que das la piel}

\section{por tus}

\section{Salvat ia da por ti.}
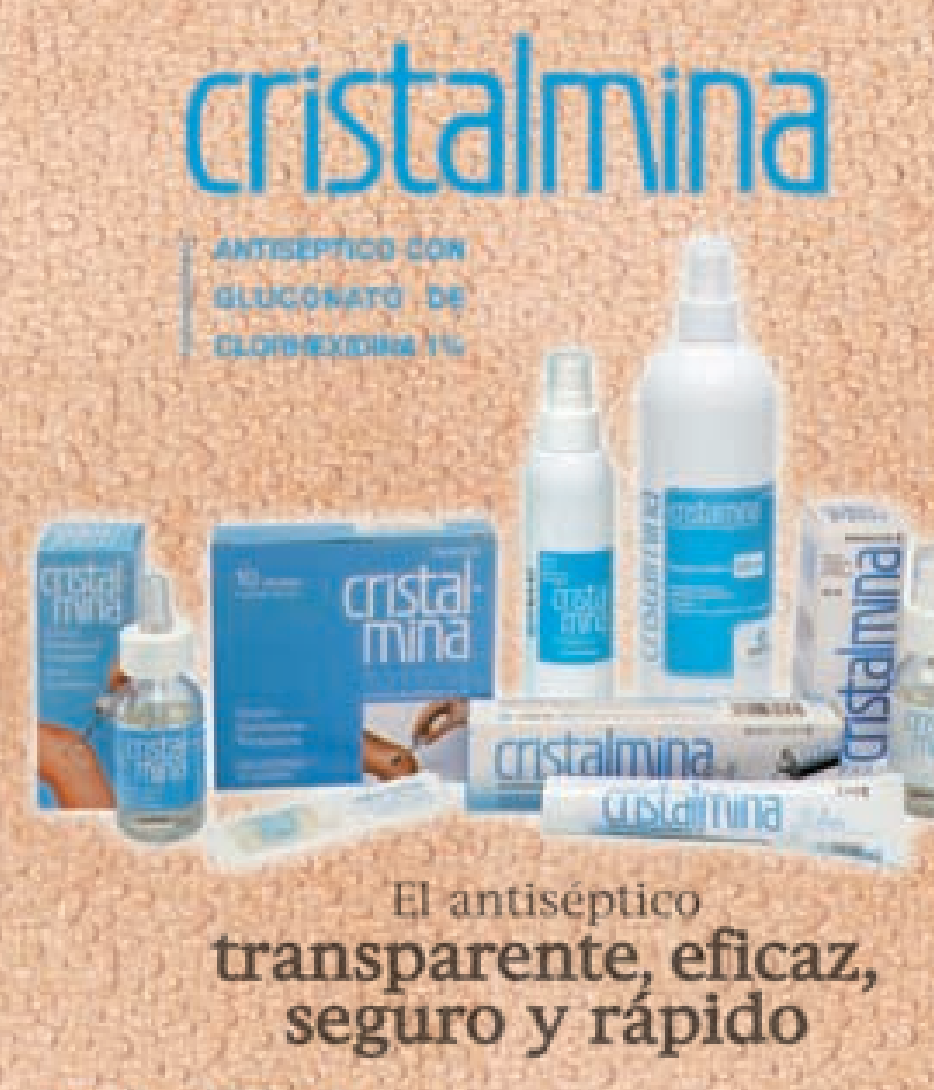

\section{transparente, eficaz, seguro y rápido}

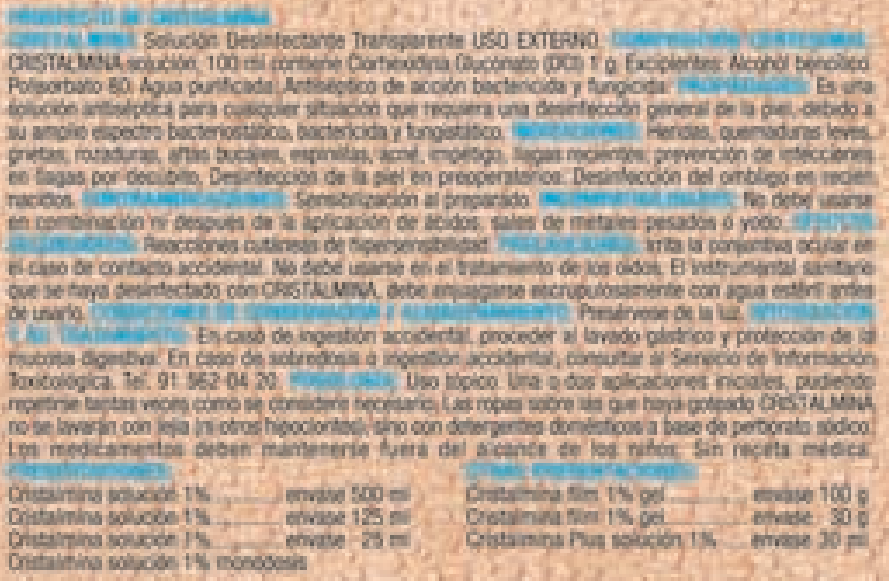

